\title{
"Mobile" Leprosy Control in the Eastern Province of Zambia. Part III*
}

C. McDOUGALL

Leprosy specialist, Department of Health, Lusaka, Zambia†

A. H. DRAKE

Leprosy Control Officer, British Leprosy Relief Association (LEPRA)

\section{Impressions of the First Year of a Joint Campaign by the Zambian Department of Health and the British Leprosy Relief Association (LEPRA)}

\section{INTRODUCTION}

In 1967 a leprologist from the World Health Organization (WHO) visited Zambia and undertook a comprehensive tour of over 9000 miles in order to examine and assess the leprosy services generally, and advise on future development. While acknowledging excellent work in some parts of the country, his report (Papinutto, 1968) rightly drew attention to an overdependence and emphasis on no fewer than 27 leprosaria, and to a general weakness in out-patient services.

By good fortune, the neighbouring country of Malawi had already established, through the British Leprosy Relief Association (LEPRA) in London, its own Leprosy Control Scheme (see Molesworth, 1969). One of us (CM) was able to visit this area in late 1967 with a view to deciding if the scheme could be modified for use in Zambia, either as a demonstration or pilot project or as a practical and economic method of leprosy control. Its introduction into Zambia has proved possible. The present paper describes the first year of operation, with emphasis on the improvement in attendance rates and the remarkable clarification of facts and statistics which has resulted.

*Received for publication 8 December, 1969.

$\dagger$ Present address: Appltree Cottage, Mallin's Lane, Longcot, nr. Faringdon, Berks.

\section{CHOICE OF PROJECT AREA}

Zambia covers over 290,586 sq. miles (over $780,000 \mathrm{sq} . \mathrm{km})$ and has a total population of just under 4 million. Apart from the Luapula Valley in the north, few areas have a regular "mobile" visiting system for out-patient control and supervision, and any one of the 8 provinces could have been chosen with benefit to some of the 15,000 leprosy out-patients already registered in this country.

However, the Eastern Province was chosen for a number of reasons, of which the chief were: (1) an excellent taried road was nearing completion and ran the whole length of the Province; (2) there was no petrol rationing in the Eastern Province at that time; (3) there was no overall Government control of leprosy and no developed out-patient supervision; (4) there was an excellent Mission leprosarium near the Provincial centre, with trained staff and a visiting surgeon highly skilled in reconstructive surgery; and (5) it was though likely that "routine" statistical reports and notifications from this area did not accurately reveal the true leprosy control situation.

\section{ORGANIZATION AND METHODS}

In June, 1968, LEPRA provided the services of an experienced leprosy control officer (A.H.D.), who had the great advantage of 
having helped with the initial planning of treatment circuits in the LEPRA Project in Malawi. His posting to Zambia was accepted on the understanding that this country would provide: (a) Zambian medical assistants prepared to learn and eventually take over the major part of the work; and (b) petrol for and maintenance of all vehicles supplied by LEPRA.

The Eastern Province covers 26,682 sq. miles $(68,000$ sq. km), of which Chipata has 7114 , Petauke 73:33, and Lundazi 12,235. A full examination was made of the 2 most southerly districts, Chipata and Petauke, in order to determine as far as was possible the village density, quality of roads, and the numbers of leprosy patients already recorded at fixed treatment centres.

The planning and organization of treatment circuits at this stage is of fundamental importance to the success or failure of the project, and a separate paper in this issue (Drake, 1970) gives details of this (see p. 107). Briefly, the Landrovers with their teams are based on either the Provincial centre or one of the district centres and make frequent, regular and closelytimed circuits of the whole area under control. The scheme started with leprosy patients already registered at fixed Government or Mission centres. They were systematically transferred to treatment points which were either in their village or very much nearer to it than the previous treatment centre. At the same time, new patients presenting spontaneously, or being referred, were registered and started on treatment.

Towards the end of 1968, 2 Landrovers were already at work on treatment runs and 664 patients had been transferred to "mobile" control. By August, 1969, 3 Landrovers were in full operation and 1093 patints were registered, with attendance rates of nearly $85 \%$ coming for treatment and $77 \%$ for patients under review only-higher figures than had ever been known before in this or other Zambian provinces.

\section{PERSONNEL}

Before this scheme was envisaged, 9 Zambian medical assistants were sent to the All-Africa Leprosy and Rehabilitation Training Centre in Addis Ababa for an intensive course in rural area supervision of leprosy. All successfully completed the course and returned to Zambia to take up positions of responsibility. Two were assigned to this project, and have very largely taken over control of their respective areas. Each Landrover carries a junior grade of worker (Tuberculosis/Leprosy Preventive Assistant) to help with records and handling of patients.

For the third district another medical assistant with good local experience of leprosy has joined the scheme, and this probably completes the present staff needs-a remarkably small and economic group for the care of well over 1000 patients in such an area.

\section{STATISTICS}

Table 1 shows the situation before patients were allocated to our mobile treatment circuits. (These figures were finally brought together towards the end of 1968.) Those for district No. 3 (Lundazi) were collected on a small number of visits and are given with considerable "benefit of the doubt"; the real attendance rates are almost certainly not as good as those expressed in this table.

'TABLE I

Total number of patients and attendances in Eastern Province prior to transfer to mobile treatment circuits, as at December, 1968. ("Regular', attendance is taken to mean attendance on $75 \%$ or more of possible occasions, and "out of control', to mean absent (or lost sight of) for 2 years or more.)

\begin{tabular}{cccccrrr}
\hline District & $\begin{array}{c}\text { No. of fixed } \\
\text { centres treating } \\
\text { leprosy }\end{array}$ & $\begin{array}{c}\text { Total leprosy } \\
\text { cases originally } \\
\text { registered }\end{array}$ & $\begin{array}{c}\text { No. } \\
\text { attending } \\
\text { regularly }\end{array}$ & $\%$ & $\begin{array}{c}\text { No. } \\
\text { attending } \\
\text { irregularly }\end{array}$ & $\begin{array}{c}\% \\
\text { No. }\end{array}$ & $\begin{array}{c}\text { Not attendingatall } \\
\text { ("out of control") }\end{array}$ \\
\hline (1) Chipata & 22 & 806 & 339 & 42 & 467 & 58 & 236 \\
(2) Petauke & 15 & 239 & 100 & 42 & 139 & 58 & 89 \\
(3) Lundazi & 17 & 212 & 123 & 58 & 89 & 42 & 69 \\
\hline
\end{tabular}


Table 2 shows the latest position as clarified by the joint scheme, approximately one year after inauguration, that is as at August, 1969. The higher total presented to us at the outset (1257 as in Table 1 ) is due to the fact that we are still unable to trace over 200 names. However, many of these patients are believed to be dead or to have left the country, or the figures may represent double (or even treble) entries for one patient.

$$
\text { TABLE } 2
$$

Figures as at August, 1969, approximately one year after the beginning of the joint GRZ-LEPRA scheme, showing numbers and percentages of patients on treatment or review, and attendance rates.

Total no. of patients registered on GRZ-LEPRA Mobile circuits - 1093

Of these

\begin{tabular}{lcc}
\hline & $N o$. & $\%$ \\
On active treatment & 960 & 88 \\
$\begin{array}{l}\text { On review only } \\
\text { Combined total of patients attending } \\
\quad \text { regularly }\end{array}$ & 133 & 12 \\
$\begin{array}{l}\text { Therefore, total not attending } \\
\text { regularly }\end{array}$ & 951 & 87 \\
\end{tabular}

\section{TREATMENT}

Treatment was started with dapsone tablets, using both 100 and $25 \mathrm{mg}$ strengths. The maximum dose for any adult was $200 \mathrm{mg}$ weekly, and this has now become standard practice throughout Zambia.

In the early stages of the scheme we contacted every patient once every 2 weeks. A dose was given with a drink of water, under direct supervision, and the following week's dose was handed to the patient in a plastic container, with careful instructions. This produced excellent contact with the people, gained their confidence, and resulted in attendance rates which were remarkably high.

However, it was felt that the second week's dose might not be taken by the patient, or taken at the wrong time. Commercially prepared reagent strips containing the usual paradimethylaminobenzaldehyde solution were tried out on several hundred leprosy patients in other provinces who were taking dapsone under direct supervision as in-patients. The strips were found to be of no value whatever; the stated colour change did not occur with the dapsone dosage being used, or was so slight that it could not be clearly distinguished from the original light yellow of the paper. This failure, and the appearance of "deputies" sent to collect dapsone on behalf of a patient, especially if they were children, acted as a warning.

In early 1969 it was decided to make plans for the conversion of a Landrover for the giving of dapsone intramuscularly. This received further impetus from the preliminary reports of the use of DADDS, a development which it was thought might have important applications in Zambia and elsewhere. There is in fact no clear evidence that dapsone is sold or otherwise misused in Zambia, but this possibility, together with wrong dosage by the patient, wrong timing and malabsorption of the drug are ruled out by use of the intramuscular route. It does raise some difficulties, however, and these are discussed in the accompanying paper by $\mathrm{Mr}$. Drake, in which the practical details of Landrover modification for giving drugs by injection are described.

\section{CLOSURE OF LEPROSARIA}

In 1968, one of the 3 Mission leprosaria in the Province was closed down. This was made possible by a number of factors, these including a great improvement in staffing and accommodation at what is now the remaining leprosarium for the Province, together with a very active programme against ulceration, with reconstructive surgery for selected cases. However, another very important factor was the out-patient service provided by GRZ-LEPRA for patients whose nearest treatment point would otherwise have been too far from their village.

In mid-1969 a second leprosarium was closed, and in this case the decisive factor was undoubtedly the provision by us of satisfactory out-patient treatment or supervision. Apart from the psychological trauma and disruption 
of family life and wage-earning which admission to a leprosarium involves, it is known to cost 10 times as much as out-patient treatment. Even in this short period, the saving to Mission and Government must already have been significant.

The remaining leprosarium in the Province is now increasingly orientated towards the admission of the "problem" case, together with offering vocational guidance, education in anaesthetic problems, reconstructive surgery, teaching, and the provision of suitable footwear. Three years ago, this leprosarium had over 160 patients with ulcer problems, whereas today there are only 16 such cases; it is in fact becoming difficult to find typical perforating ulcers for teaching purposes.

\section{CASE-FINDING}

The WHO (1966) estimate for leprosy prevalence in Zambia was between 1 and 4.9 per 1000 of the population, and the likely figure for the Eastern Province is certainly not greater than this. Indeed, on the evidence so far, the prevalence in this area must be classed as low, and accordingly even more emphasis will now be given to the examination of contacts of infectious cases as the most likely productive group for case-finding. During the year, large numbers of schoolchildren and villagers have been examined; the figures for these, together with the numbers of confirmed cases presenting voluntarily at treatment points, are shown in Table 3.

In the year ending December, 1967, the Province notified 137 new cases of leprosy. In the first, somewhat tentative, year of the

TABLE 3

Case-finding, GRZ-LFPRA, August, 1968, to August, 1969, in schoolchildren, villagers, and patients presenting voluntarily.

\begin{tabular}{lccc}
\hline \multicolumn{1}{c}{ Group examined } & No. & $\begin{array}{c}\text { Leprosy cases } \\
\text { found }\end{array}$ & $\%$ \\
\hline $\begin{array}{l}\text { Schoolchildren } \\
\text { Village examinations }\end{array}$ & 9431 & 21 & 0.2 \\
$\begin{array}{c}\text { Patients presenting } \\
\text { voluntarily }\end{array}$ & About 225 & 148 & - \\
\hline
\end{tabular}

present scheme 190 cases have been notified, of whom no fewer than 148 of the patients fresented themselves voluntarily at treatment points for diagnosis and advice.

\section{HEALTH EDUCATION}

Thousands of posters in the local dialect explaining the main signs of leprosy have been distributed, mainly to schools. The $16-\mathrm{mm}$ colour and sound film by LEPRA entitled Out-patients not Outcasts has been shown to thousands of schoolchildren, accompanied by a talk and discussion by a leprosy officer.

A short booklet, explaining in very simple terms the main facts about leprosy, has been written in the local dialect for the Adult Literacy Campaign, and 15,000 copies have been distributed in this Province through the Department of Community Development. Though unassessed as yet, this channel of communication and health education in leprosy could prove of lasting value, for the booklet has been accepted as standard reading material for adult literacy classes in Zambia, and is being printed in all the other main Zambian dialects.

\section{RE-ASSESSMENT OF REGISTERED CASES}

Only one of the 3 leprosaria in this Province had a programme of recall and re-assessment, and this was the one which now remains. For the purposes of re-assessment, journeys from the village to the leprosarium and back of nearly 400 miles $(640 \mathrm{~km})$ were not unusual. In 1967 alone, 77 patients travelled some 13,860 miles $(22,000 \mathrm{~km})$ for this purpose. In contrast, by the end of 1969 it is expected that GRZLEPRA will have reviewed and re-assessed about 1000 patients near their homes or in their villages at various points on the mobile treatment circuits. Comparison shows that at least twice the number of patients can be reviewed in this way at one-quarter of the cost in a given 12-month period.

Bacteriological examination, as elsewhere in rural areas of leprosy control in Zambia, has never been a strong point in this Province. However, the vast majority of all patients so far registered have at some time or other had 
slit-skin smears taken at a leprosarium, and a trained member of the team is now doing this working during treatment circuits and reviews. WHO standards for clinical and bacteriological "inactivity" are being followed.

\section{DISCUSSION}

To people working in equatorial Africa and other hyperendemic areas, the figures presented in this paper will seem absurdly small. It is our belief, however, that big figures are not important in this context, and that what matters is the method of approach and whether or not it works.

These first-year impressions are presented because the results so far seem both practical and economic. In addition, the modifications used for a comparatively sparsely populated area could prove of importance if DAIDDS comes into general use. It is conceivable that the most effective and economical way of ensuring that antileprosy treatment is taken "early, regularly and for long enough" might be the injection of a correct dose of very longacting dapsone into each patient intramuscularly. For in an area of the kind here described, with difficult roads and a hazardous wet season, there are serious limitations to the frequent supervision of oral treatment.

Mobile leprosy control is certainly not a new idea. Zambia has copied this scheme from the work of LEPRA in Malawi (to whom very full acknowledgement is due) and it is possible that they in turn had in mind the remarkable service in Ghana (Gold Coast) from 1955 to 1966. In the early years of this Ghana scheme, following a welcome delivery of 14 Landrovers from UNICEF, about 36000 patients were receiving satisfactory out-patient treatment with dapsone (McElvie, personal communication). Jarison (1968) has drawn attention to the use of mobile teams in equatorial Africa and Madagascar in bringing treatment to 150,000 leprosy patients "who had hitherto not been included in any census or been under medical supervision of any kind-for fear of being shut up in leprosy hospitals".
Preliminary discussions are already welladvanced for expansion of the present pattern of work into another province of Zambia. Meanwhile in the Eastern Province serious thought is being given to the complete integration of the work into the general health services before the end of the third year of operation. Before the end of the second year it should be possible to reach a decision about the size of the leprosy problem generally and the likely prevalence of the disease, based on known registered cases, examination of contacts, and school and village examinations.

The absence of any initial investigation into individual and community attitudes to leprosy is in retrospect considered to have been a basic error. Little is known of this aspect of leprosy work in Zambia, and an enquiry lasting 6 to 12 months by an experienced officer would not only have made the pathway easier for this control scheme, but would also have given valuable information in the matter of casefinding. Even at this stage, however, an application has been made for a health educationalist to undertake this work and also to examine the next province under consideration. The third year of "handing back" leprosy control to the general services may well be the most difficult, but could be greatly helped by basic information on attitudes to leprosy combined with a healtheducation programme aimed at the general public, schools, political organizations, and the medical staff who will be re-involved with this work.

At the outset of this scheme it was not known how LEPRA might best contribute to leprosy control in the area chosen. The Association has of course provided not only :3 Landrovers, but also the services and salary of an experienced leprosy control officer. Apart from these considerable gifts the scheme, after one year of operation, appears to contribute mainly as follows: (1) a clear demonstration of how the work should be done; (2) a great improvement in facts, figures, statistics, reports; (3) a great saving in money, as compared with the conventional leprosarium approach; (4) the pro- 
duction of high attendance rates due to close and repeated contact with the patients; and (5) a medium of great potential value for health education.

Finally, the experience gained with the modification of Landrovers for giving intramuscular injection and for "mobile" re-assessments may prove to have useful application elsewhere.

\section{SUMMARY}

The first year of a leprosy control project in the Eastern Province of Zambia is described.

This project is a co-operative one between the Department of Health in Zambia and the British Leprosy Relief Association in London, and is modelled on the latter's LEPRA Control Project in Malawi.

One year after the start of the joint project, 2 out of 3 leprosaria in the Province have been closed, attendance rates have improved very greatly, and remarkable changes in statistical information have been revealed.

Experience has been gained in the practical details of Landrover modification for intramuscular injection of dapsone, and it is thought that this might have wider application if DAIDDS lives up to its present expectations.

As the second year of the work proceeds, plans are being made to extend the work into another Province (Luapula). Meanwhile, careful thought is being given to 2 aspects of the work: (a) an estimate of the leprosy prevalence in the Province and a further definition of the overall size of the leprosy problem; and (b) the total re-integration of leprosy control into the general medical services before the end of the third year of operation.

\section{ACKNOWLEDGEMENTS}

We are indebted to the Permanent Secretary of the Department of Health, Lusaka, and to the British Leprosy Relief Association, London, for permission to publish this article.

We wish to record that the present scheme in Zambia is based almost entirely on the parent LEPRA Control Project in Malawi, at present under the direction of Dr. B. D. Molesworth.

Lastly, we thank Mr. Lloyd Stone, Mr. Alexander Kamanga, and Mr. Akabana Mulundumina for their enthusiastic co-operation in the work described.

\section{REFERENCES}

JARISON, J. F. ( 1968). WHO Official Recorils, No. 169, Geneva.

LEPrA (1966). Forty-third Annual Report, Lonclon. mCelvie, A. (1969)). Personal communication.

molesworth, B. D. (1969). LHPRA Control Project in Malawi. Lepr. Rev. 40, 237.

NINTH INTERNATIONAL LEPROSY CONGRESS, LONDON (1968). Abstracts in Int. .J. Lepr. 36, 533-685.

PAPINUTTO, J. (1968). Report on a mission in Zambia. WHO, AFR/LEP/25 Rev. I, Geneva.

WORLD HEALTH ORGANIZATION (1966). Guide to Leprosy Control. WHO, Geneva. 